\section{Occult Head Injury}

\author{
Matthew R. Powell ${ }^{1}$ and Michael McCrea ${ }^{2}$ \\ ${ }^{1}$ Clinical Neuropsychologist, Division of \\ Neurocognitive Disorders, Department of \\ Psychiatry and Psychology, Mayo Clinic, \\ Rochester, MN, USA \\ ${ }^{2}$ Department of Neurosurgery, Medical College of \\ Wisconsin, Milwaukee, WI, USA
}

\section{Definition}

An occult head injury refers to a brain injury not readily apparent when a patient presents for physical examination. Symptoms may be subtle, particularly early on, and the mechanism of injury may not be reported by the patient or collateral, particularly if the injury was due to abuse or neglect (Christian et al. 2009; Narang and Clarke 2014; Paul and Adamo 2014). Mental status changes, nausea and vomiting, difficulty breathing, excessive crying, other bone fractures, and retinal hemorrhage are indicators of possible brain injury and suggest screening should occur (Paul and Adamo 2014). Infants, very young children, and children presenting from lower socioeconomic households have higher risk for occult head injury (Narang and Clarke 2014). Children with challenging developmental or medical histories are also at greater risk (Paul and Adamo 2014).

\section{Cross-References}

- Concussion

- Mild (Traumatic) Brain Injury

- Traumatic Brain Injury

\section{References and Readings}

Christian, C. W., Block, R., Committee on Child, A, \& Neglect, \& American Academy of, P. (2009). Abusive head trauma in infants and children. Pediatrics, 123(5), 1409-1411. doi:10.1542/peds.2009-0408.

Narang, S., \& Clarke, J. (2014). Abusive head trauma: Past, present, and future. Journal of Child Neurology, 29(12), 1747-1756. doi:10.1177/0883073814549995.

Paul, A. R., \& Adamo, M. A. (2014). Non-accidental trauma in pediatric patients: A review of epidemiology, pathophysiology, diagnosis and treatment. Translational Pediatrics, 3(3), 195-207. doi:10.3978/j.issn. 2224-4336.2014.06.01. 